\title{
Biodistribution, Radiation Dosimetry, and Clinical Application of a Melanin-Targeted PET Probe, ${ }^{18}$ F-P3BZA, in Patients
}

\author{
Xiaowei Ma*1,2, Shengjun Wang*1, Shuailiang Wang ${ }^{1}$, Daliang Liu ${ }^{1}$, Xiaohu Zhao ${ }^{1}$, Hao Chen $^{2}$, Fei Kang ${ }^{1}$, \\ Weidong Yang ${ }^{1}$, Jing Wang ${ }^{1}$, and Zhen Cheng ${ }^{2}$ \\ ${ }^{1}$ Department of Nuclear Medicine, Xijing Hospital, Fourth Military Medical University, Xi'an, China; and ${ }^{2}$ Molecular Imaging \\ Program at Stanford (MIPS), Bio-X Program, and Department of Radiology, Canary Center at Stanford for Cancer Early Detection, \\ Stanford University, Stanford, California
}

$\mathrm{N}$-(2-(diethylamino)-ethyl)- ${ }^{-18} \mathrm{~F}-5$-fluoropicolinamide $\left({ }^{18} \mathrm{~F}-\mathrm{P} 3 \mathrm{BZA}\right)$ is a radiotracer that demonstrates high binding selectivity and affinity in melanoma. The aim of the present study was to estimate the biodistribution and clinical radiation dosimetry of ${ }^{18} \mathrm{~F}-\mathrm{P} 3 \mathrm{BZA}$ in healthy volunteers and perform a preliminary clinical application for PET/CT imaging in melanoma patients. Methods: ${ }^{18} \mathrm{~F}-\mathrm{P} 3 \mathrm{BZA}$ was produced efficiently with a radiosynthesizer. Six healthy volunteers were injected with ${ }^{18} \mathrm{~F}-\mathrm{P} 3 \mathrm{BZA}(211.7 \pm 15.4 \mathrm{MBq})$ followed by serial whole-body $\mathrm{PET} / \mathrm{CT}$ scans and blood tests to assess biodistribution, pharmacokinetic, and radiation dosimetry at $10 \mathrm{~min}, 1 \mathrm{~h}, 2 \mathrm{~h}$, and $4 \mathrm{~h}$ after injection. The vital signs of volunteers were recorded in regular intervals during the imaging sessions. The effective dose for each subject after the medical internal radiation dosimetry schema was calculated with OLINDA/EXM software. For the preliminary clinical application, 5 patients with suspected melanomas underwent ${ }^{18} \mathrm{~F}-\mathrm{P} 3 \mathrm{BZA}$ PET/CT imaging at $10 \mathrm{~min}$ and $1 \mathrm{~h}$ after injection. All patients also underwent ${ }^{18} \mathrm{~F}-\mathrm{FDG} \mathrm{PET} / \mathrm{CT}$ scans on the third day to compare the potential diagnostic ability of ${ }^{18} \mathrm{~F}-\mathrm{P} 3 \mathrm{BZA}$ with ${ }^{18} \mathrm{~F}-\mathrm{FDG}$. Results: The radiochemistry yield of ${ }^{18} \mathrm{~F}-\mathrm{P} 3 \mathrm{BZA}$ labeling was $12.3 \% \pm 3.9 \%$, and the purity of ${ }^{18} \mathrm{~F}-\mathrm{P} 3 \mathrm{BZA}$ after purification and formulation was higher than $99.5 \%$. The highest uptake of ${ }^{18} \mathrm{~F}-\mathrm{P} 3 \mathrm{BZA}$ was in the liver with an $\mathrm{SUV}_{\text {mean }}$ of $8.3 \pm 1.0$ at $10 \mathrm{~min}$ after injection. The resultant whole-body effective dose was $0.0193 \mathrm{mSv} / \mathrm{MBq} .{ }^{18} \mathrm{~F}-\mathrm{P} 3 \mathrm{BZA}$ showed high uptake and suggested an ability for specific imaging of melanoma and its metastasis in patients. The average SUV mean of ${ }^{18} \mathrm{~F}-\mathrm{P} 3 \mathrm{BZA}$ and ${ }^{18} \mathrm{~F}-\mathrm{FDG}$ in tumors was $19.7 \pm 5.3$ and $10.8 \pm 2.7$ at 60 min after injection. Conclusion: Our study suggests that ${ }^{18} \mathrm{~F}-\mathrm{P} 3 \mathrm{BZA}$ is safe and compatible for clinical use. The first-in-human clinical application to melanoma showed favorable delineated tumors in patients, demonstrating the potential of ${ }^{18} \mathrm{~F}-\mathrm{P} 3 \mathrm{BZA}$ for diagnostic PET imaging of melanoma.

Key Words: ${ }^{18} \mathrm{~F}-\mathrm{P} 3 \mathrm{BZA}$; radiation dosimetry; melanoma; PET/CT imaging; clinical transfer

J Nucl Med 2019; 60:16-22

DOI: 10.2967/jnumed.118.209643

Received Feb. 8, 2018; revision accepted May 23, 2018.

For correspondence or reprints contact either of the following: Zhen Cheng, Molecular Imaging Program at Stanford, Canary Center at Stanford for Cancer Early Detection, Department of Radiology and Bio-X Program, Stanford University, 1201 Welch Rd., Lucas Expansion, P095, Stanford, CA 94305. E-mail: zcheng@stanford.edu

Jing Wang, Department of Nuclear Medicine, Xijing Hospital, Fourth Military Medical University, Xi'an 710032, China.

E-mail: wangjing@fmmu.edu.cn

${ }^{*}$ Contributed equally to this work

Published online May 31, 2018.

COPYRIGHT (c) 2019 by the Society of Nuclear Medicine and Molecular Imaging.
$\mathbf{M}$ alignant melanoma is one of the most aggressive and dangerous types of skin cancers, and there has been an increase in its incidence worldwide (1). More than $3.4 \%$ of patients diagnosed with a single melanoma developed a second primary melanoma within 2 y (2-4). Unfortunately, patients with multiple primary melanomas have significantly worse survival than those with a single melanoma (5). However, the overall 5-y survival rate can reach $98 \%$ if the melanoma can be detected at its earliest stages and removed surgically. Therefore, development of specific molecular imaging probes to both detect melanoma at its earliest stages and detect the metastasis of melanoma is critical for improving the survival of patients with malignant melanoma.

$\mathrm{PET} / \mathrm{CT}$ is a powerful molecular imaging tool that plays a critical role in diagnosis and treatment response evaluation in malignancies, including melanoma $(6,7)$. ${ }^{18} \mathrm{~F}-\mathrm{FDG}$ is routinely used for PET/CT imaging of stage III/IV malignant melanoma (detection of distant metastases) and for therapeutic monitoring (8). However, ${ }^{18} \mathrm{~F}$-FDG is nonspecific and not sensitive enough for the detection of primary melanoma and metastases in stage I/II melanomas (9). Thus, many radiolabeled PET imaging probes, such as antibodies, peptides, and small molecules associated with malignant melanoma, have been developed for melanoma imaging (10-13). Among those targeting compounds, radiolabeled benzamide analogs showed promising specificity and high binding affinity to the melanin pigment that is overproduced in melanomas of mice xenografts (14-19).

Melanin pigment exists in most melanoma lesions, and only $2 \%-8 \%$ of melanomas are amelanotic (lacking either pigment on visual inspection or melanin in the pathology) $(20,21)$. Furthermore, melanin can also regulate epidermal homeostasis and thus affect melanoma behavior $(22,23)$ and the outcome of radiotherapy (24); melanin production shortens overall survival and disease-free survival in patients with metastatic melanoma. Thus, melanin is a very important target for melanoma diagnosis and therapy effect estimation. Our group has designed and synthesized a series of ${ }^{18} \mathrm{~F}$-labeled benzamide analog probes for PET imaging on the basis of the picolinamide structure, which targets melanin for melanoma diagnosis. We found that $N$-(2-(diethylamino)-ethyl)- ${ }^{18} \mathrm{~F}-$ 5-fluoropicolinamide ( $\left.{ }^{18} \mathrm{~F}-\mathrm{P} 3 \mathrm{BZA}\right)$ had high specificity and favorable pharmacokinetic properties for binding with melanin and demonstrated good potential for PET imaging of melanoma $(25,26)$.

Given the potential of ${ }^{18} \mathrm{~F}-\mathrm{P} 3 \mathrm{BZA}$ for imaging melanoma in a clinical setting, in this study we further optimized the radiochemistry of ${ }^{18} \mathrm{~F}-\mathrm{P} 3 \mathrm{BZA}$ to make the synthesis faster, automatic, and 
TABLE 1

Demographics of Study Subjects

\begin{tabular}{lcccc}
\hline Patient no. & Age $(\mathrm{y})$ & Sex & Weight $(\mathrm{kg})$ & $\begin{array}{c}\text { Injected } \\
\text { dose }(\mathrm{MBq})\end{array}$ \\
\hline 1 & 55 & $\mathrm{~F}$ & 55 & 187 \\
2 & 61 & $\mathrm{~F}$ & 59 & 210 \\
3 & 42 & $\mathrm{~F}$ & 51 & 204 \\
4 & 49 & $\mathrm{M}$ & 75 & 229 \\
5 & 63 & $\mathrm{M}$ & 66 & 214 \\
6 & 57 & $\mathrm{M}$ & 70 & 226 \\
Mean & $54.5 \pm 7.8$ & - & $62.6 \pm 9.2$ & $211.7 \pm 15.4$ \\
\hline
\end{tabular}

compatible for clinical use. For clinical translation purposes, we presented the first-in-human biodistribution and effective radiation dose of ${ }^{18} \mathrm{~F}-\mathrm{P} 3 \mathrm{BZA}$ to various organs and whole body in 6 healthy volunteers by performing a series of whole-body PET imaging after intravenous injection of ${ }^{18} \mathrm{~F}-\mathrm{P} 3 \mathrm{BZA}$. Then, to our knowledge for the first time, we preliminarily investigated the clinical value of ${ }^{18} \mathrm{~F}-\mathrm{P} 3 \mathrm{BZA}$ by performing both ${ }^{18} \mathrm{~F}-\mathrm{P} 3 \mathrm{BZA}$ and ${ }^{18} \mathrm{~F}-\mathrm{FDG}$ PET/ $\mathrm{CT}$ imaging on 5 patients with suspected melanomas and verified the diagnosis with pathology.

\section{MATERIALS AND METHODS}

\section{Healthy Volunteers and Patients}

This study was approved by the Independent Ethics Committee of Xijing Hospital (no. KY20151230-1) and was registered at ClinicalTrials.gov (NCT03033485). Six healthy volunteers (age range, 42-63 y; 3 men and 3 women; Table 1) were recruited for biodistribution and radiation dosimetry in this study, and 5 patients with suspected melanomas (age range, 43-66 y; 3 men and 2 women; Table 2) were recruited for preliminary clinical application of ${ }^{18} \mathrm{~F}-\mathrm{P} 3 \mathrm{BZA}$. All of the patients were randomly chosen from the clinic when they first came to the hospital and were preliminarily diagnosed with melanoma according to a visual examination. They did not receive any kind of therapy before PET/CT imaging. They gave written informed consent before inclusion, in accordance with the recommendation for Good Clinical Practice by Xijing Hospital. None of the subjects demonstrated any clinically significant abnormalities before examinations. All patients underwent pathology examinations after the imaging studies.

\section{Radiochemistry of ${ }^{18} \mathrm{~F}-\mathrm{P} 3 \mathrm{BZA}$}

The synthesis scheme of ${ }^{18} \mathrm{~F}-\mathrm{P} 3 \mathrm{BZA}$ is shown in Figure $1 .{ }^{18} \mathrm{~F}-$ fluoride was produced via the $\left[{ }^{18} \mathrm{O}(\mathrm{p}, \mathrm{n}){ }^{18} \mathrm{~F}\right]$ nuclear reaction with cyclotron (HM-12 s; Sumitomo). ${ }^{18} \mathrm{~F}-\mathrm{P} 3 \mathrm{BZA}$ was synthesized on an AllInOne Synthesizer (Triasis) using an automatic procedure that was optimized according to our previous radiolabeling method, a 1-step bromine-for-fluorine nucleophilic substitution (Supplemental Table 1; Supplemental Figure 1 [supplemental materials are available at http:// jnm.snmjournals.org]) (25).

\section{Biodistribution, Dosimetry, and Safety of ${ }^{18} \mathrm{~F}-\mathrm{P} 3 \mathrm{BZA}$ in Healthy Volunteers}

The biodistribution and dosimetry procedure (Fig. 2) was designed according to a reported method (27). ${ }^{18} \mathrm{~F}-\mathrm{P} 3 \mathrm{BZA}$ in the range of 187$229 \mathrm{MBq}$ (average dose, $211.7 \pm 15.4 \mathrm{MBq}$; Table 1) was injected to healthy volunteers through a venous line into the arm within $30 \mathrm{~s}$. Serial whole-body PET/CT scans were acquired on a dedicated PET/ CT scanner (Biograph 40 system; Siemens Medical Solutions) at 10, 60, 120, and 240 min after injection. The uptake of each major organ was calculated by drawing a volume of region over the major organs on the basis of the contour of CT images according to the requirement of the medical internal radiation dosimetry method. Urine samples were collected before each PET/CT scan and were measured for radioactivity concentration in a calibrated 256-Channel $\gamma$-counter (Capintec, Inc., USA). The number of integrations of the bladders was calculated using the International Commission on Radiological Protection 30 urinary bladder model as implemented in OLINDA/EXM software (version 1.1; Vanderbilt University).

For pharmacokinetic analysis, a 2-mL blood sample was obtained before every imaging session and tested for radioactive counts with the $\gamma$-counter. Then the blood sample was centrifuged $(3,500 \mathrm{rpm}$, $5 \mathrm{~min}$ ), and the supernatant plasma was collected to count radioactivity. The distribution ratio between blood cells and plasma was calculated from the activity concentrations of whole blood and plasma at each time point according the method described by Jim et al. (28). Time-activity curves for the blood and plasma were then plotted with GraphPad Prism 7.0 (GraphPad Software Inc.).

The effective doses of major organs were calculated using the OLINDA/EXM software by modifying the standard reference phantoms with subject-specific masses $(27,29)$. Since eyes were not included in the OLINDA/EXM system, the effective dose of the eyes was calculated according to the reported method $(30,31)$. Safety data, including vital signs (heart rate, blood pressure, respiratory rate, body temperature, and skin color) and electrocardiograms, were recorded before and $5 \mathrm{~h}$ after injection.

TABLE 2

Demographics of Patients

\begin{tabular}{lcccccc}
\hline & & & & & & \multicolumn{2}{c}{ Injected dose (MBq) } \\
\cline { 6 - 7 } Patient no. & Age $(\mathrm{y})$ & Sex & Stage $^{*}$ & Weight $(\mathrm{kg})$ & 18F-P3BZA & 18 F-FDG \\
\hline 1 & 49 & M & II & 72 & 219 & 381 \\
2 & 66 & F & III & 52 & 162 & 266 \\
3 & 59 & M & IV & 66 & 210 & 363 \\
4 & 43 & M & III & 75 & 226 & 444 \\
5 & 56 & F & II & 57 & 177 & 292 \\
Mean & $54.6 \pm 8.9$ & - & - & $64.4 \pm 9.8$ & $198.8 \pm 27.9$ & $349.2 \pm 71.4$
\end{tabular}

${ }^{*}$ Cancer stages of patients were decided after the pathology examination. 


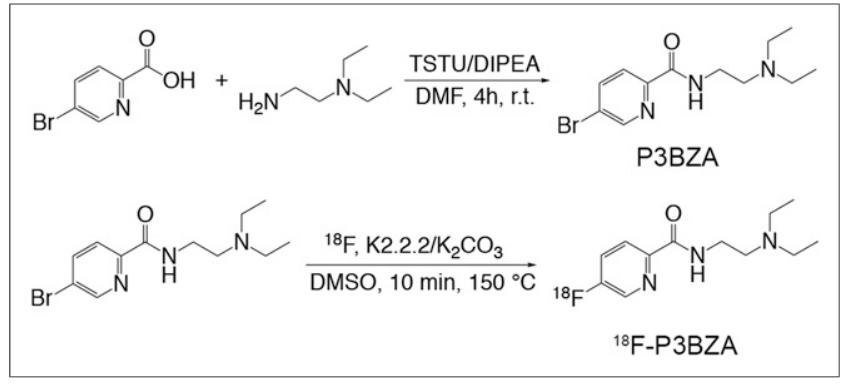

FIGURE 1. ${ }^{18} \mathrm{~F}-\mathrm{P} 3 \mathrm{BZA}$ synthesis scheme.

\section{PET/CT Scans of Melanoma Patients}

All 5 patients underwent both ${ }^{18} \mathrm{~F}-\mathrm{P} 3 \mathrm{BZA}$ and ${ }^{18} \mathrm{~F}-\mathrm{FDG} \mathrm{PET} / \mathrm{CT}$ scans with a 2-d interval between procedures (Fig. 2). The dosages for ${ }^{18} \mathrm{~F}-\mathrm{P} 3 \mathrm{BZA}$ and ${ }^{18} \mathrm{~F}-\mathrm{FDG}$ were 3.1 and $5.55 \mathrm{MBq} / \mathrm{kg}$, respectively (exact doses are shown in Table 2). Two cycles of PET/CT scans of the whole body were acquired 10 and $60 \mathrm{~min}$ after intravenous injection of ${ }^{18} \mathrm{~F}-\mathrm{P} 3 \mathrm{BZA}$. Two days later, ${ }^{18} \mathrm{~F}-\mathrm{FDG}$ PET/CT scans were obtained at $60 \mathrm{~min}$ after injection. All PET/CT images were acquired and reconstructed with the same parameters as the method used for healthy volunteer imaging as described above. The uptake of primary tumors, metastases, and major organs were analyzed by drawing volume of regions. All PET/CT images were also independently reviewed by 3 highly experienced certified specialists in nuclear medicine.

\section{Immunohistochemical Staining}

A few days after PET/CT imaging, patients bearing a single primary melanoma underwent standard surgery to resect the tumor. For patients bearing metastases, biopsies were performed on one of the major lesions, and the sample was subsequently analyzed by standard hematoxylin and eosin (H\&E) and immunohistochemistry staining. Resected tissue was analyzed by standard H\&E and immunohistochemistry staining to verify the PET/CT findings.

\section{Statistics}

All statistical analyses were performed using GraphPad Prism 7.0 for MAC OS X. All data are presented as mean \pm SD.

\section{RESULTS}

\section{Radiochemistry of ${ }^{18} \mathrm{~F}-\mathrm{P} 3 \mathrm{BZA}$}

The overall radiosynthesis time using the AllInOne Synthesizer is about $54 \mathrm{~min}$, including labeling, purification, and formulation

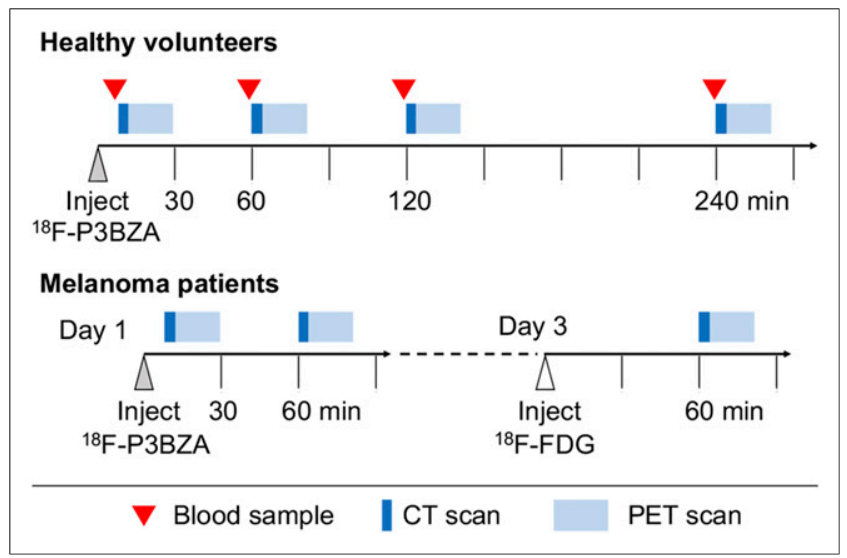

FIGURE 2. Timeline of the dosimetry study (upper part) and melanoma (lower part) PET/CT imaging. processes. The radiochemical yield (not decay corrected) of ${ }^{18} \mathrm{~F}$ P3BZA was $12.3 \% \pm 3.9 \%(n=6)$, and the radiochemical purity tested by representative radio semipreparative high-pressure liquid chromatograph was greater than $99.5 \%$ in all batches. The specific activity was $131.9 \pm 24.6 \mathrm{GBq} / \mu \mathrm{mol}(n=6)$, which was calculated according to the chromatograph from the representative radio-semipreparative high-pressure liquid chromatograph by coinjection of ${ }^{18} \mathrm{~F}-\mathrm{P} 3 \mathrm{BZA}$ and ${ }^{19} \mathrm{~F}-\mathrm{P} 3 \mathrm{BZA}$. The in vivo stability was higher than $94 \%$ after $4 \mathrm{~h}$ after injection. The analytic representative radio-semipreparative high-pressure liquid chromatographs are shown in Supplemental Figure 2.

\section{Biodistribution, Safety, and Dosimetry in Healthy Volunteers}

During the study, no immediate adverse events were observed for any subjects, including both healthy volunteers and melanoma patients. No significant changes in the vital signs (heart rate, blood pressure, respiratory rate, body temperature, and skin color) and electrocardiograms were observed during the imaging period, indicating that the imaging dose of ${ }^{18} \mathrm{~F}-\mathrm{P} 3 \mathrm{BZA}$ was safe and tolerable.

The maximum-intensity-projection images of ${ }^{18} \mathrm{~F}-\mathrm{P} 3 \mathrm{BZA}$ at 4 different time points after administration in healthy volunteers are presented in Figure 3. Prominent accumulation of ${ }^{18} \mathrm{~F}-\mathrm{P} 3 \mathrm{BZA}$ was observed in the liver, kidneys, stomach, spleen, and bladder at each time point after injection, followed by a quick decrease over the remainder of the study due to radioactivity elimination through the liver and kidneys. The highest uptake of ${ }^{18} \mathrm{~F}-\mathrm{P} 3 \mathrm{BZA}$ is in the liver, with an $\mathrm{SUV}_{\text {mean }}$ of $8.3 \pm 1.0$ at 10 min after injection. The blood analysis result (Supplemental Fig. 3) showed 6.2\% $\pm 1.1 \%$ and $3.6 \% \pm 0.7 \%$ of the peak radioactivity remained in circulation at 10 and $240 \mathrm{~min}$ after injection, respectively, indicating ${ }^{18} \mathrm{~F}$ P3BZA was quickly cleared from the blood pool.

Moderate uptake was observed in the brain, eyes, and bone marrow, and low uptake was observed in the lungs and muscle. The time-distribution pattern of ${ }^{18} \mathrm{~F}-\mathrm{P} 3 \mathrm{BZA}$ in the brain was shown in Figure 4A. The $\mathrm{SUV}_{\text {mean }}$ in the brain was $3.5 \pm 0.4$, $2.0 \pm 0.2,1.7 \pm 0.2$, and $1.4 \pm 0.2$ at 10,60, 120, and $240 \mathrm{~min}$,

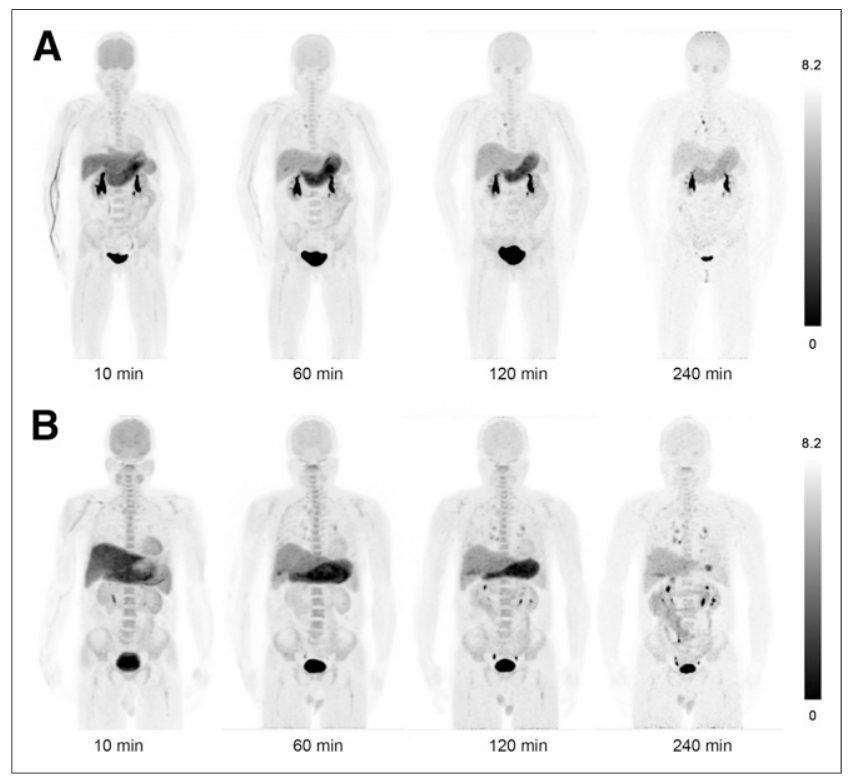

FIGURE 3. Maximum-intensity-projection PET images at different time points after ${ }^{18} \mathrm{~F}-\mathrm{P} 3 \mathrm{BZA}$ injection in female subject $(\mathrm{A})$ and male subject $(\mathrm{B})$. 


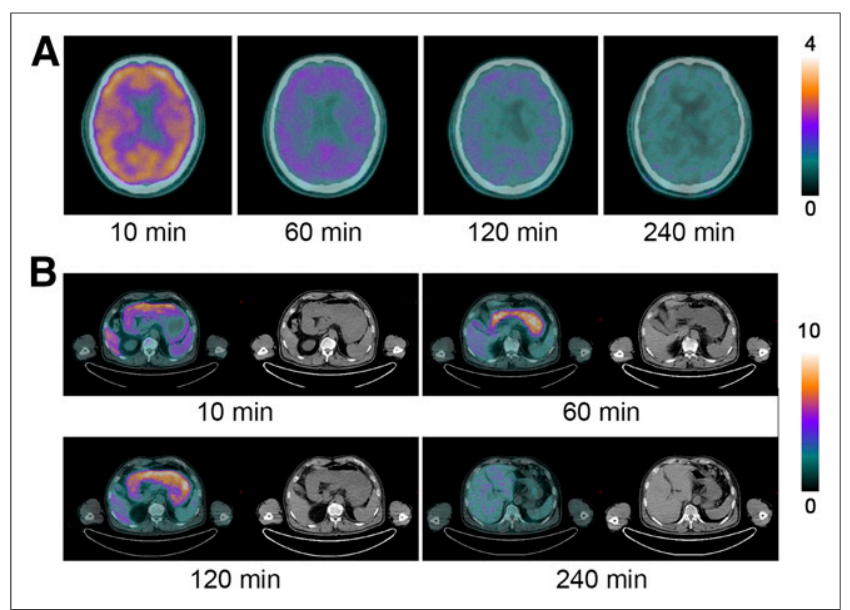

FIGURE 4. Transverse images of brain (A) and stomach (B) at different time points after ${ }^{18} \mathrm{~F}-\mathrm{P} 3 \mathrm{BZA}$ injection.

respectively. The ${ }^{18} \mathrm{~F}-\mathrm{P} 3 \mathrm{BZA}$ was cleared quickly from most of the brain regions after $120 \mathrm{~min}$. Because of melanin pigment accumulation, the eyes showed a distinctive uptake of $1.6 \pm$ $0.3,2.1 \pm 0.4,2.4 \pm 0.5$, and $2.2 \pm 0.3$ at 10, 60, 120, and $240 \mathrm{~min}$, respectively. Moderate uptake was also observed in the regional obsolete lymph nodes that showed calcification in the chest. Supplemental Figure 4 shows a representative image of ${ }^{18}$ F-P3BZA uptake in lymph nodes.

${ }^{18} \mathrm{~F}-\mathrm{P} 3 \mathrm{BZA}$ was mostly cleared through the kidneys, resulting in high accumulation in the kidneys and bladder. A special uptake was observed in the stomach (Fig. 4B); ${ }^{18}$ F-P3BZA quickly accumulated in the stomach lining within the first 10 min after injection. By $60 \mathrm{~min}$, the probe had fully secreted into the cavity. After 240 min the probe was completely expelled from the stomach. The average $\mathrm{SUV}_{\text {mean }}$ of the stomach was $10.9 \pm 1.1$ at $60 \mathrm{~min}$ after injection. The time-radioactivity curves of the decaycorrected uptake of each organ are shown in Figure 5 (specific values are listed in Supplemental Table 2).

The average absorbed dose estimates overall in healthy participants are listed in Table 3 . The bladder wall received the highest dose of all organs $(0.12 \mathrm{mSv} / \mathrm{MBq})$, reflecting renal tracer clearance. The absorbed dose of the eyes was $0.0128 \mathrm{mSv} / \mathrm{MBq}$. The other major organs that received relatively high doses were the liver (0.0407 $\mathrm{mSv} / \mathrm{MBq})$ and spleen $(0.0247 \mathrm{mSv} / \mathrm{MBq})$. The mean effective dose of ${ }^{18} \mathrm{~F}-\mathrm{P} 3 \mathrm{BZA}$ was $0.0193 \mathrm{mSv} / \mathrm{MBq}$. With an average injected ${ }^{18} \mathrm{~F}-\mathrm{P} 3 \mathrm{BZA}$ dose of $204 \mathrm{MBq}$, the volunteer received an effective dose of $3.94 \mathrm{mSv}$.

\section{PET/CT Scans of Melanoma Patients}

To assess the clinical transfer potential of ${ }^{18} \mathrm{~F}-\mathrm{P} 3 \mathrm{BZA}$, we investigated the tumor uptake of ${ }^{18} \mathrm{~F}-\mathrm{P} 3 \mathrm{BZA}$ in malignant melanoma tissues of 5 patients before surgical intervention and compared these with ${ }^{18} \mathrm{~F}-\mathrm{FDG}$ PET/CT imaging results. Uptake by primary tumors, axillary lymph nodes, and metastases was clearly visualized at both the 10 -min and the $1-\mathrm{h}{ }^{18} \mathrm{~F}-\mathrm{P} 3 \mathrm{BZA}$ PET/CT scans and on the ${ }^{18} \mathrm{~F}-$ FDG PET/CT scan at 60 min after injection (Fig. 6; Supplemental Table 2).

Both ${ }^{18} \mathrm{~F}-\mathrm{P} 3 \mathrm{BZA}$ and ${ }^{18} \mathrm{~F}-\mathrm{FDG}$ PET/CT detected 5 primary melanomas, 2 lymph node metastases, and 1 bone metastasis total. The average $\mathrm{SUV}_{\max }$ of primary tumors was $19.7 \pm 5.3$ for ${ }^{18} \mathrm{~F}-$ P3BZA PET and $10.8 \pm 2.7$ for ${ }^{18} \mathrm{~F}-\mathrm{FDG}$ PET at $60 \mathrm{~min}$ after injection. The average $\mathrm{SUV}_{\max }$ of metastases was $18.2 \pm 3.7$ for
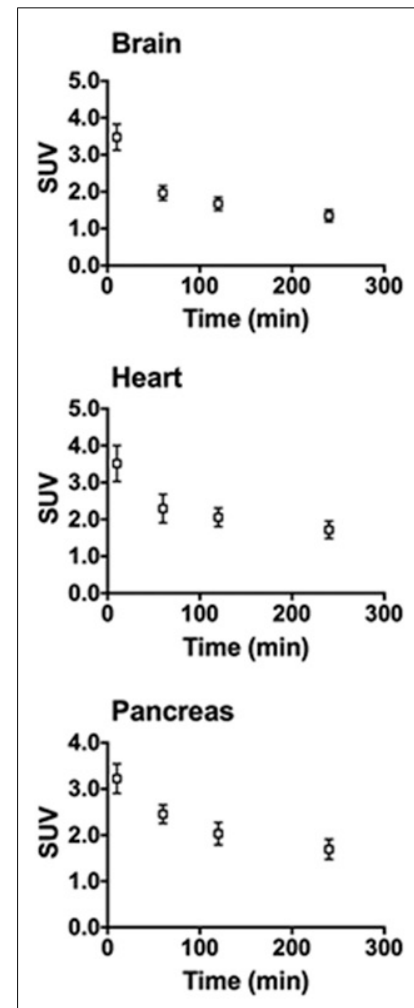
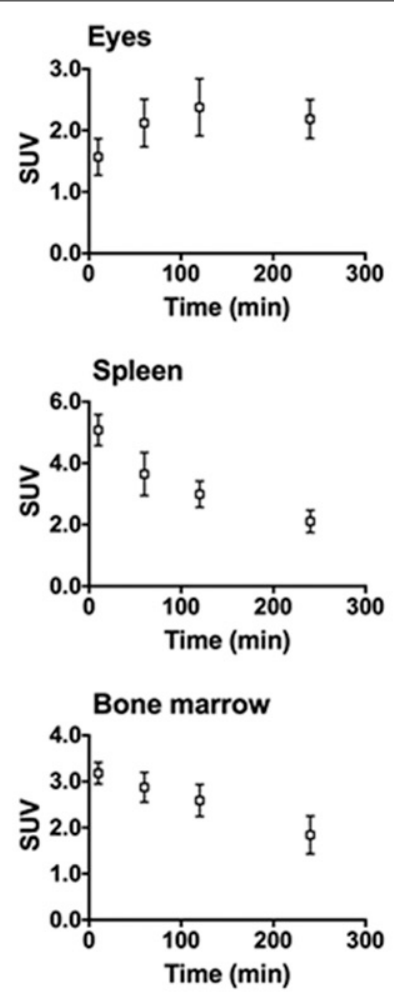
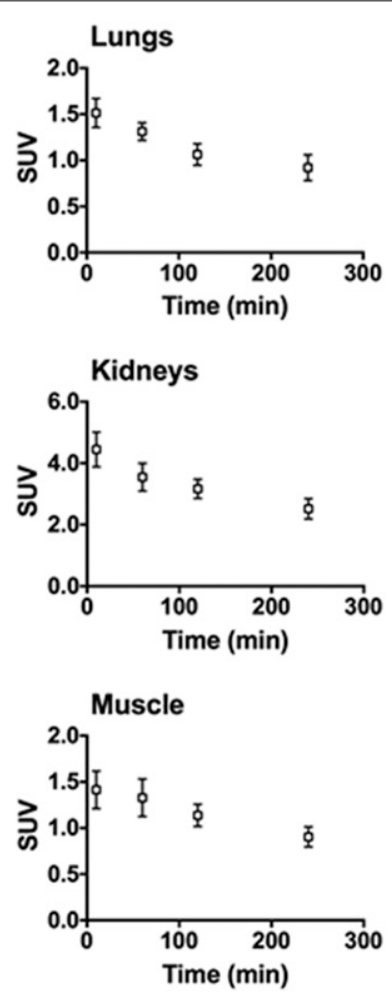
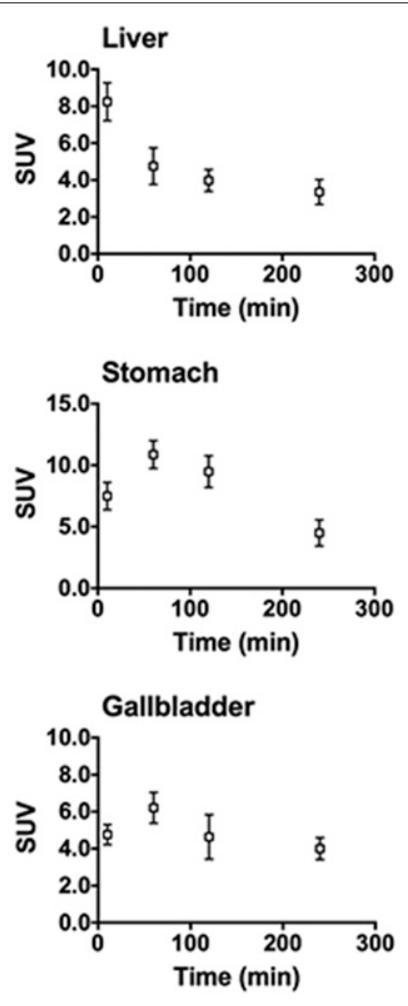

FIGURE 5. Average time-SUV mean curves $(n=6)$ for 12 major organs (error bars indicate $\pm S D)$. 
TABLE 3

Estimated Absorbed Radiation Dose for ${ }^{18} \mathrm{~F}-\mathrm{P} 3 \mathrm{BZA}$

\begin{tabular}{|c|c|}
\hline Organ & Dose $(\mathrm{mSv} / \mathrm{MBq})$ \\
\hline Adrenals & 0.0150 \\
\hline Brain & 0.0147 \\
\hline Breasts & 0.0075 \\
\hline Gallbladder wall & 0.0158 \\
\hline Lower large intestine wall & 0.0134 \\
\hline Small intestine & 0.0207 \\
\hline Stomach wall & 0.0219 \\
\hline Upper large intestine wall & 0.0228 \\
\hline Heart wall & 0.0166 \\
\hline Kidneys & 0.0218 \\
\hline Liver & 0.0407 \\
\hline Lungs & 0.0121 \\
\hline Muscle & 0.0120 \\
\hline Ovaries $(n=3)$ & 0.0109 \\
\hline Pancreas & 0.0224 \\
\hline Red marrow & 0.0122 \\
\hline Osteogenic cells & 0.0085 \\
\hline Skin & 0.0034 \\
\hline Spleen & 0.0247 \\
\hline Testes $(n=3)$ & 0.0086 \\
\hline Thymus & 0.0051 \\
\hline Thyroid & 0.0110 \\
\hline Urinary bladder wall & 0.1200 \\
\hline Uterus & 0.0141 \\
\hline Eyes & 0.0128 \\
\hline Total body & 0.0099 \\
\hline Effective dose & 0.0193 \\
\hline
\end{tabular}

${ }^{18} \mathrm{~F}-\mathrm{P} 3 \mathrm{BZA}$ PET and $6.3 \pm 2.2$ for ${ }^{18} \mathrm{~F}-\mathrm{FDG}$ PET. Moreover, the uptake of ${ }^{18} \mathrm{~F}-\mathrm{P} 3 \mathrm{BZA}$ in the liver, spleen, kidneys, stomach, and other normal organs was conspicuously decreased whereas the accumulation of the probe in tumors and metastases increased significantly after $60 \mathrm{~min}$, which produced a higher tumor-to-muscle ratio at $60 \mathrm{~min}$ than that at $10 \mathrm{~min}(18.5 \pm 4.8 \mathrm{vs} .8 .0 \pm 3.2)$ and also much higher than the ratio at 60 -min ${ }^{18} \mathrm{~F}-\mathrm{FDG}$ PET imaging $(18.5 \pm 4.8$ vs. $10.3 \pm 3.9)$. The highest uptake was found in a patient with melanoma at stage IV. The maximumintensity-projection and axial transverse images of this patient at 10- and 60-min ${ }^{18}$ F-P3BZA and 60-min ${ }^{18}$ F-FDG PET are shown in Figures 7A and 7B, respectively. The primary melanoma located at the right lower alveolar, lymph node metastasis, and bone metastasis at the second lumbar vertebra were clearly delineated, with an $\mathrm{SUV}_{\text {mean }}$ of $10.9,9.4$, and 8.6 on 60 -min ${ }^{18} \mathrm{~F}-\mathrm{P} 3 \mathrm{BZA}$ PET and 7.7, 8.7 , and 5.8 on $60-\mathrm{min}{ }^{18} \mathrm{~F}-\mathrm{FDG}$ PET, respectively. The primary lesion was confirmed with final $\mathrm{H} \& \mathrm{E}$ and immunohistochemistry staining, as shown in Figure 7C.

\section{Immunohistochemical Staining}

Melanoma tissues from all 5 patients were analyzed by standard $\mathrm{H} \& \mathrm{E}$ and immunohistochemistry staining. All primary tumors showed high melanin content.

\section{DISCUSSION}

In this clinical trial study, we evaluated the first-in-human safety, pharmacokinetics, biodistribution, and radiation dosimetry of a specific melanoma-targeted PET/CT imaging probe, ${ }^{18} \mathrm{~F}-\mathrm{P} 3 \mathrm{BZA}$, in 6 healthy human participants. We also investigated the preliminary application of ${ }^{18} \mathrm{~F}-\mathrm{P} 3 \mathrm{BZA}$ for melanoma imaging in 5 patients with melanoma. The tracer was well tolerated, and no adverse effects or clinical changes in vital signs were observed. The whole-body effective dose was favorable, equaling $3.94 \mathrm{mSv}$ at an injected activity of approximately $204 \mathrm{MBq}$ as normal dosage. This is lower than the reported dose of ${ }^{18} \mathrm{~F}-\mathrm{FDG}$, for which the effective dose is approximately $9.0 \pm 1.6 \mathrm{mSv}$ at an average clinical dose of $450 \pm 32 \mathrm{MBq}$ (32). Although ${ }^{18} \mathrm{~F}-\mathrm{P} 3 \mathrm{BZA}$ shows moderate uptake in eyes, the absorbed dose is acceptable and safe according to the reference published by the International Commission on Radiological Protection (33). Thus, ${ }^{18} \mathrm{~F}-\mathrm{P} 3 \mathrm{BZA}$ is safe for clinical use, and the estimated radiation dose is acceptable.

The ${ }^{18}$ F-P3BZA biodistribution in healthy volunteers showed the primary clearance route was through the hepatobiliary system and renal pathway. The primary uptake of ${ }^{18} \mathrm{~F}-\mathrm{P} 3 \mathrm{BZA}$ is distinctly visible in images at all time points in those tissues known to have a high concentration of melanin, such as the eyes and scalp. The accumulation in eyes is a characteristic uptake of ${ }^{18} \mathrm{~F}-\mathrm{P} 3 \mathrm{BZA}$ because of the pigmented structures in the eyes, including choroidal melanocytes and retinal pigment cells (34).

High uptake was also observed in the stomachs of all healthy volunteers and melanoma patients. From the distribution pattern of ${ }^{18} \mathrm{~F}-\mathrm{P} 3 \mathrm{BZA}$ in the stomach, it can be observed that the probe quickly accumulated in the stomach wall after injection, then secreted into the lumen and cleared rapidly. More importantly, none of the healthy volunteers and melanoma patients indicated any stomach discomfort after injection. We are undertaking further studies to figure out the mechanism for accumulation and secretion of ${ }^{18} \mathrm{~F}-\mathrm{P} 3 \mathrm{BZA}$ in the stomach.

To assess the potential of ${ }^{18} \mathrm{~F}-\mathrm{P} 3 \mathrm{BZA}$ as a specific PET tracer for melanoma imaging, we enrolled 5 patients for ${ }^{18} \mathrm{~F}-\mathrm{P} 3 \mathrm{BZA}$ and ${ }^{18} \mathrm{~F}-$ FDG PET/CT imaging. The results showed that ${ }^{18} \mathrm{~F}-\mathrm{P} 3 \mathrm{BZA}$ distributes to the melanoma quickly and demonstrates a high tumor uptake and tumor-to-muscle ratio after injection.

${ }^{18} \mathrm{~F}-\mathrm{FDG} \mathrm{PET} / \mathrm{CT}$ is valuable for melanoma diagnosis and therapeutic effect evaluation in the clinic. However, ${ }^{18}$ F-FDG imaging has limitations, such as the false-positive of inflammation, and the substantially lower tumor-tomuscle contrast of ${ }^{18} \mathrm{~F}-\mathrm{FDG}$ PET, compared with that of ${ }^{18}$ F-P3BZA. By specifically targeting

FIGURE 6. Average SUV
stases in patients $(n=5)$.

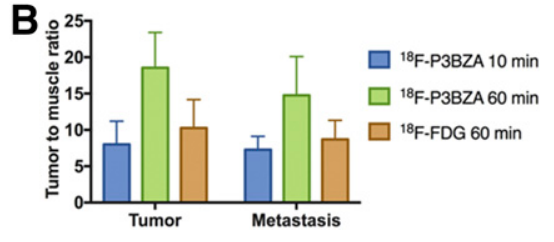

(A) and tumor-to-muscle ratio (B) of melanoma tumors and meta- 


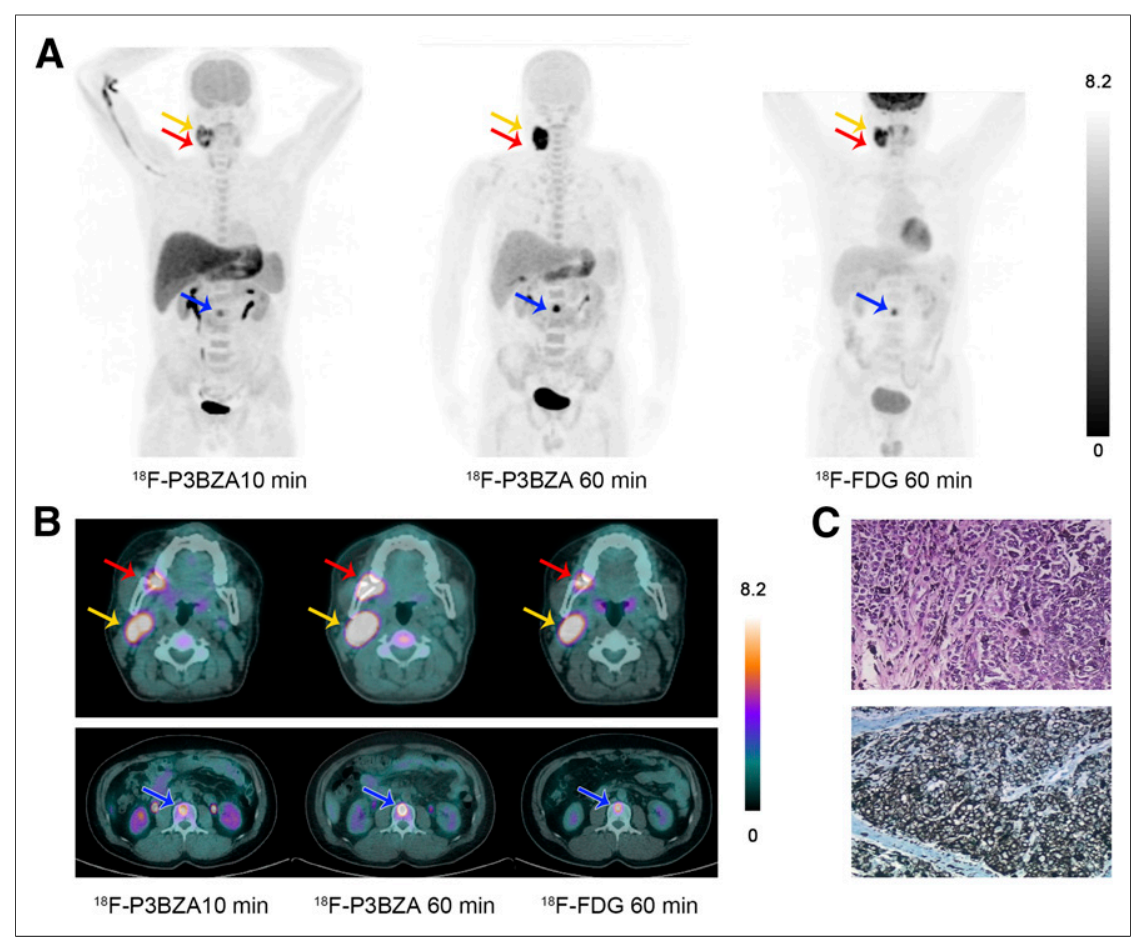

FIGURE 7. Sample images of a melanoma patient. (A) Maximum-intensity-projection PET images at 10 and $60 \mathrm{~min}$ after ${ }^{18} \mathrm{~F}-\mathrm{P} 3 \mathrm{BZA}$ injection and at $60 \mathrm{~min}$ after ${ }^{18} \mathrm{~F}-\mathrm{FDG}$ injection. (B) Transverse images of primary melanoma (red arrow), lymph node metastasis (yellow arrow), and bone metastasis (blue arrow). (C) H\&E (upper part) and immunohistochemistry (lower part) images of primary melanoma.

\section{ACKNOWLEDGMENTS}

We gratefully acknowledge Dr. Xiaoping Hu from Beijing PET Technology Co., Ltd., for his technical support on the AllinOne ${ }^{\mathrm{TM}}$ Synthesizer, Dr. Jing Wu from AMS Pharmaceutical Group Corporation for ${ }^{18} \mathrm{~F}$ supply, and Mei Yang for injection. We also acknowledge Kelton Schleyer and Philip Deenik from The University of New Mexico for text editing.

\section{REFERENCES}

1. Siegel RL, Miller KD, Jemal A. Cancer statistics, 2016. CA Cancer J Clin. 2016;66:7-30.

2. DiFronzo LA, Wanek LA, Morton DL. Earlier diagnosis of second primary melanoma confirms the benefits of patient education and routine postoperative follow-up. Cancer. 2001;91:1520-1524.

3. Buljan M, Situm M, Bolanca Z, Zivkovic MV, Mihic LL. Multiple primary melanoma: epidemiological and prognostic implications; analysis of 36 cases. Coll Antropol. 2010;34(suppl 2):131-134.

4. Menzies S, Barry R, Ormond P. Multiple primary melanoma: a single centre retrospective review. Melanoma Res. 2017;27:638-640.

5. Youlden DR, Baade PD, Soyer HP, et al. Ten-year survival after multiple invasive melanomas is worse than after a single melanoma: a population-based study. J Invest Dermatol. 2016;136:2270-2276.

6. Mena E, Sanli Y, Marcus C, Subramaniam RM. Precision medicine and PET/computed tomography in melanoma. PET Clin. 2017;12:449-458.

7. Petersen H, Holdgaard PC, Madsen PH, et al. FDG melanin, ${ }^{18} \mathrm{~F}-\mathrm{P} 3 \mathrm{BZA}$ showed the potential to improve the accuracy of diagnosing melanoma and its metastasis by PET/CT imaging. Additionally, most melanomas have a high accumulation of melanin, making ${ }^{18} \mathrm{~F}-\mathrm{P} 3 \mathrm{BZA}$ a potential probe for both early and advanced melanoma diagnosis.

In this preliminary study, 1 limitation is that only 5 patients were enrolled for the diagnostic estimation and all of the primary melanomas are melanin-enriched. No amelanotic melanoma was enrolled; thus, we cannot present the diagnostic ability of ${ }^{18} \mathrm{~F}-\mathrm{P} 3 \mathrm{BZA}$ in amelanotic melanoma in this study.

\section{CONCLUSION}

The present whole-body biodistribution and dosimetry study demonstrated that ${ }^{18} \mathrm{~F}-\mathrm{P} 3 \mathrm{BZA}$ is safe and suitable for human PET/CT imaging. In the preliminary clinical pilot ${ }^{18} \mathrm{~F}-\mathrm{P} 3 \mathrm{BZA}$ and ${ }^{18} \mathrm{~F}-\mathrm{FDG}$ PET imaging study of melanoma patients, ${ }^{18} \mathrm{~F}-\mathrm{P} 3 \mathrm{BZA}$ showed a selective and rapid uptake in melanoma and metastases along with a favorable whole-body distribution pattern in vivo, suggesting a potential use for melanoma diagnosis and treatment effect evaluation in the clinic.

\section{DISCLOSURE}

This study was supported by grants from the National Natural Science Foundation of China (81501501), the Key Program of National Natural Science Foundation of China (81230033), Shaanxi Science \& Technology Co-ordination \& Innovation Project (2016KTCQ03-09), the International Cooperation Program of Xijing Hospital (XJZT15G01), and the Office of Science (BER), U.S. Department of Energy (DE-SC0008397). No other potential conflict of interest relevant to this article was reported.
PET/CT in cancer: comparison of actual use with literature-based recommendations. Eur J Nucl Med Mol Imaging. 2016;43:695-706.

8. Schüle SC, Eigentler TK, Garbe C, la Fougere C, Nikolaou K, Pfannenberg C. Influence of ${ }^{18} \mathrm{~F}$-FDG PET/CT on therapy management in patients with stage III/ IV malignant melanoma. Eur J Nucl Med Mol Imaging. 2016;43:482-488.

9. Belhocine T, Pierard G, De Labrassinne M, Lahaye T, Rigo P. Staging of regional nodes in AJCC stage I and II melanoma: 18FDG PET imaging versus sentinel node detection. Oncologist. 2002;7:271-278.

10. Voss SD, Smith SV, DiBartolo N, et al. Positron emission tomography (PET) imaging of neuroblastoma and melanoma with ${ }^{64} \mathrm{Cu}-\mathrm{SarAr}$ immunoconjugates. Proc Natl Acad Sci USA. 2007;104:17489-17493.

11. Cheng Z, Xiong Z, Subbarayan M, Chen X, Gambhir SS. ${ }^{64} \mathrm{Cu}-$ labeled alphamelanocyte-stimulating hormone analog for microPET imaging of melanocortin 1 receptor expression. Bioconjug Chem. 2007;18:765-772.

12. Kato K, Kubota T, Ikeda M, et al. Low efficacy of ${ }^{18} \mathrm{~F}$-FDG PET for detection of uveal malignant melanoma compared with ${ }^{123}$ I-IMP SPECT. J Nucl Med. 2006;47:404-409.

13. Gao F, Sihver W, Jurischka C, et al. Radiopharmacological characterization of ${ }^{64} \mathrm{Cu}$-labeled alpha-MSH analogs for potential use in imaging of malignant melanoma. Amino Acids. 2016;48:833-847.

14. Chezal JM, Papon J, Labarre P, et al. Evaluation of radiolabeled (hetero)aromatic analogues of $\mathrm{N}$-(2-diethylaminoethyl)-4-iodobenzamide for imaging and targeted radionuclide therapy of melanoma. J Med Chem. 2008;51:3133-3144.

15. Larisch R, Schulte KW, Vosberg H, Ruzicka T, Muller-Gartner HW. Differential accumulation of iodine-123-iodobenzamide in melanotic and amelanotic melanoma metastases in vivo. $J$ Nucl Med. 1998;39:996-1001.

16. Kertész I, Vida A, Nagy G, et al. In vivo imaging of experimental melanoma tumors using the novel radiotracer ${ }^{68} \mathrm{Ga}-\mathrm{NODAGA}$-procainamide (PCA). J Cancer. 2017;8:774-785.

17. Garg PK, Nazih R, Wu Y, Singh R, Garg S. $4-{ }^{11}$ C-methoxy $N$-(2-diethylaminoethyl) benzamide: a novel probe to selectively target melanoma. J Nucl Med. 2017;58:827-832.

18. Garg PK, Nazih R, Wu Y, Grinevich VP, Garg S. Selective targeting of melanoma using $\mathrm{N}$-(2-diethylaminoethyl) 4 - $\left[{ }^{18} \mathrm{~F}\right]$ fluoroethoxy benzamide $\left(4-\left[{ }^{18} \mathrm{~F}\right]\right.$ FEBZA): a novel PET imaging probe. EJNMMI Res. 2017;7:61-71.

19. Rizzo-Padoin N, Chaussard M, Vignal N, et al. $\left[{ }^{18} \mathrm{~F}\right] \mathrm{MEL} 050$ as a melanintargeted PET tracer: fully automated radiosynthesis and comparison to ${ }^{18} \mathrm{~F}-\mathrm{FDG}$ for the detection of pigmented melanoma in mice primary subcutaneous tumors and pulmonary metastases. Nucl Med Biol. 2016;43:773-780. 
20. Thomas NE, Kricker A, Waxweiler WT, et al. Comparison of clinicopathologic features and survival of histopathologically amelanotic and pigmented melanomas: a population-based study. JAMA Dermatol. 2014;150:1306-1314.

21. Gualandri L, Betti R, Crosti C. Clinical features of 36 cases of amelanotic melanomas and considerations about the relationship between histologic subtypes and diagnostic delay. J Eur Acad Dermatol Venereol. 2009;23:283-287.

22. Brożyna AA, Jozwicki W, Carlson JA, Slominski AT. Melanogenesis affects overall and disease-free survival in patients with stage III and IV melanoma. Hum Pathol. 2013;44:2071-2074.

23. Sarna M, Zadlo A, Hermanowicz P, Madeja Z, Burda K, Sarna T. Cell elasticity is an important indicator of the metastatic phenotype of melanoma cells. Exp Dermatol. 2014;23:813-818.

24. Brożyna AA, Jozwicki W, Roszkowski K, Filipiak J, Slominski AT. Melanin content in melanoma metastases affects the outcome of radiotherapy. Oncotarget. 2016;7:17844-17853.

25. Liu H, Liu S, Miao Z, et al. Development of ${ }^{18} \mathrm{~F}$-labeled picolinamide probes for PET imaging of malignant melanoma. J Med Chem. 2013;56:895-901.

26. Bu L, Li R, Liu H, et al. Intrastriatal transplantation of retinal pigment epithelial cells for the treatment of Parkinson disease: in vivo longitudinal molecular imaging with ${ }^{18}$ F-P3BZA PET/CT. Radiology. 2014;272:174-183.

27. Hsiao IT, Lin KJ, Huang KL, et al. Biodistribution and radiation dosimetry for the Tau rracer ${ }^{18}$ F-THK-5351 in healthy human subjects. J Nucl Med. 2017;58:1498-1503.
28. O'Doherty J, Jauregui-Osoro M, Brothwood T, et al. ${ }^{18} \mathrm{~F}$-Tetrafluoroborate, a PET probe for imaging sodium/iodide symporter expression: whole-body biodistribution, safety, and radiation dosimetry in thyroid cancer patients. $J$ Nucl Med. 2017;58:1666-1671.

29. Stabin MG, Sparks RB, Crowe E. OLINDA/EXM: the second-generation personal computer software for internal dose assessment in nuclear medicine. $\mathrm{J} \mathrm{Nucl}$ Med. 2005;46:1023-1027.

30. Bolch WE, Dietze G, Petoussi-Henss N, Zankl M. Dosimetric models of the eye and lens of the eye and their use in assessing dose coefficients for ocular exposures. Ann ICRP. 2015;44:91-111.

31. McCollough CH, Schueler BA. Calculation of effective dose. Med Phys. 2000; 27:828-837.

32. Quinn B, Dauer Z, Pandit-Taskar N, Schoder H, Dauer LT. Radiation dosimetry of ${ }^{18}$ F-FDG PET/CT: incorporating exam-specific parameters in dose estimates. BMC Med Imaging. 2016;16:41-51.

33. Stewart FA, Akleyev AV, Hauer-Jensen M, et al. ICRP publication 118: ICRP statement on tissue reactions and early and late effects of radiation in normal tissues and organs-threshold doses for tissue reactions in a radiation protection context. Ann ICRP. 2012;41:1-322.

34. Chehade F, Michelot J, Hindie E, et al. Localization of N-(2-diethylaminoethyl) 4-iodobenzamide in the pigmented mouse eye: a microanalytical study. Cell Mol Biol (Noisy-le-grand). 1996;42:343-350. 